\title{
Teaching K-8 Students Engineering Design Process through Zoombinis
}

\author{
Mrs. Anna Newley, American College of Education \\ Mr. Erdogan Kaya, University of Nevada, Las Vegas
}

Kaya is a $\mathrm{PhD}$ student in science education at University of Nevada, Las Vegas. He is working as a research assistant and teaching science methods courses. Prior to beginning the $\mathrm{PhD}$ program, he received his MS degree in computer science and engineering and holds a BS degree in chemical engineering. He taught K-12 STEM+CS for seven years. Additionally, he coached robotics teams and was awarded several grants that promote Science, Technology, Engineering, and Mathematics (STEM) and Computer Science(CS) education. He is also interested in improving STEM+CS education for minorities. He has been volunteering in many education outreach programs including Science Fair and Robotics programs such as First Robotics competitions. Areas of research interest include engineering education, STEM+CS, and robotics in K-12 education. Kaya advocates his view that research, teaching and learning are best practiced as a unified enterprise that benefits students and society. He has received numerous teaching awards as well as grants for his research from several foundations. Kaya is an active member of AERA, ASEE, ASTE, NARST, NSTA, and CSTA, has presented at over 15 conferences, published in ranked journals (e.g. Journal of College Science Teaching), reviewed conference proposals (e.g ASEE).

\section{Dr. Hasan Deniz, University of Nevada Las Vegas}

Hasan Deniz is an Associate Professor of Science Education at University of Nevada Las Vegas. He teaches undergraduate, masters, and doctoral level courses in science education program at University of Nevada Las Vegas. His research agenda includes epistemological beliefs in science and evolution education. He is recently engaged in professional development activities supported by several grants targeting to increase elementary teachers' knowledge and skills to integrate science, language arts, and engineering education within the context of Next Generation Science Standards.

\section{Miss Ezgi Yesilyurt, University of Nevada, Las Vegas}

Ezgi Yesilyurt is a $\mathrm{PhD}$ student in curriculum and instruction/science education at University of Nevada, Las Vegas. She is working as a graduate assistant and teaching science methods courses. She received her MS degree and BS degree in elementary science education. She participated European Union Projects in which she conducted series of professional development programs for in-service science teachers. Areas of research interest are engineering education, inquiry learning and evolution education. 


\section{Teaching Middle School Students Engineering Design Process with Video Games}

\section{Introduction:}

In this poster, we will present Zoombinis (Figure 1, and 3), a video game to engage students in engineering design process.

Video games offer affordances for STEM education:

- Potential for teaching and learning

- Improving the skills of learners in the classroom

- Continuous formative assessment

- Instantaneous feedback on skills

Video games are more capable of improving:

- Decision-making and problem solving skills

- Conceptual understanding and process and skills in STEM.

Authors believe that serious video games should be integrated in

K-8 science and engineering classrooms.

- Limited evidence of using video games in K-8 engineering education.

- Integrating video games in K-8 engineering education is a novel way to introduce the concepts of engineering design process

- Teachers can address Next Generation Science Standards (NGSS)

- Engineering design process is defined as the process of "solving problems, designing systems, and understanding human behavior (NGSS Lead States, 2013)

- The impact of integration of EDP in science classrooms is important to improve students' understanding of Engineering (Newley et al., 2017).

- Introducing video games in science classrooms is important to spark middle and high school students' interest in Science, Technology, Engineering and Mathematics [STEM] and Computer Science (CS) (Smaldone et al., 2016).

- NGSS calls for the integration of EDP within science teaching (NGSS Lead States, 2013).

\section{Purpose/Aim:}

To what extent will middle school students understanding of engineering design process (EDP) change after a four week intervention with video games?

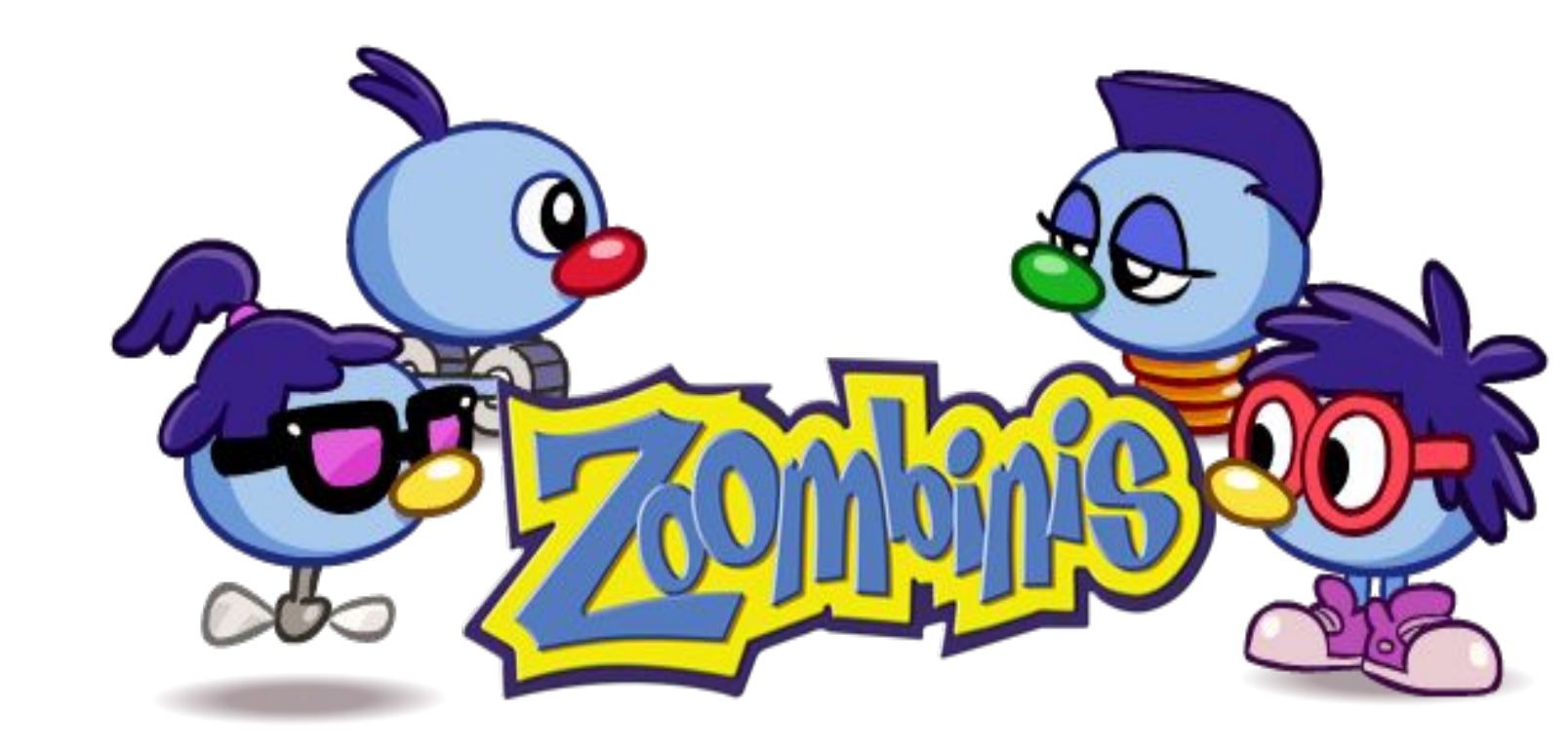

$$
\begin{aligned}
& \text { Figure 1: Zoombinis. retrieved from } \\
& \text { http://www.encore.com/p-768-zoombinis.aspx }
\end{aligned}
$$

\section{Methods:}

- Participants:

SSA-Phoenix Middle School Students

- Title 1

- $100 \%$ free and reduced lunch

- 6th through 8th grade

Instructor

- Co-author

- 11 years teaching experience

- 5 years experience teaching EiE EDP

- Intervention:

Four weeks

- Two days

One hour each day

Paired groups

First author created EDP Zoombini notebook (Figure 2)

- Data Collection

pre and post EDP test

Semi-structured pre and post interview

Control Group (Implicit Learning)

Experimental Group (Explicit-Reflective Instruction)

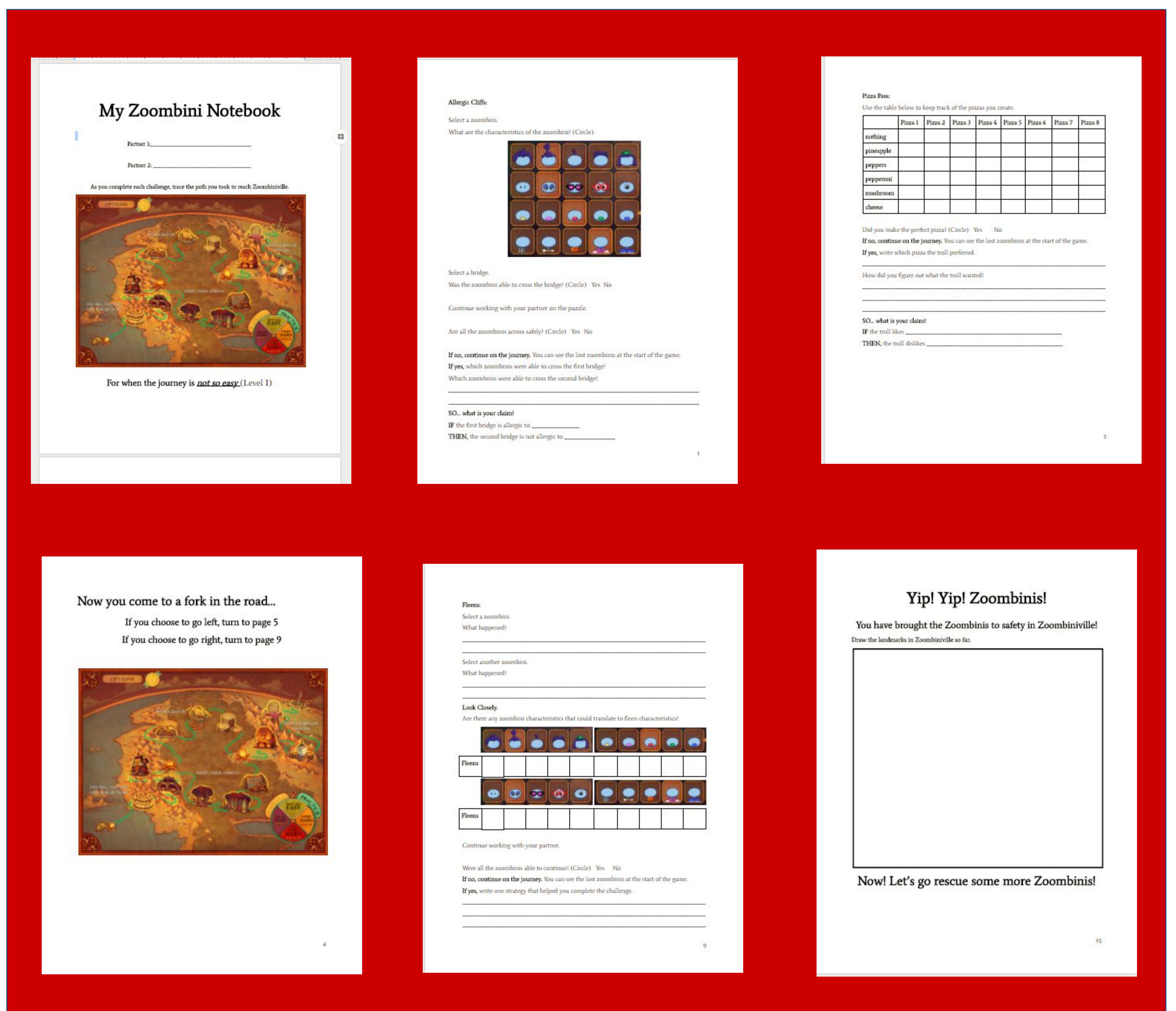

Figure 2: Zoombinis Notebook

\section{Discussion:}

- NGSS EDP and EiE EDP were combined to create a holistic approach to understanding the EDP for middle school students at all academic levels (See Figure 4 and 5).

- The data collection is currently in process, final results will be reported in a later paper.

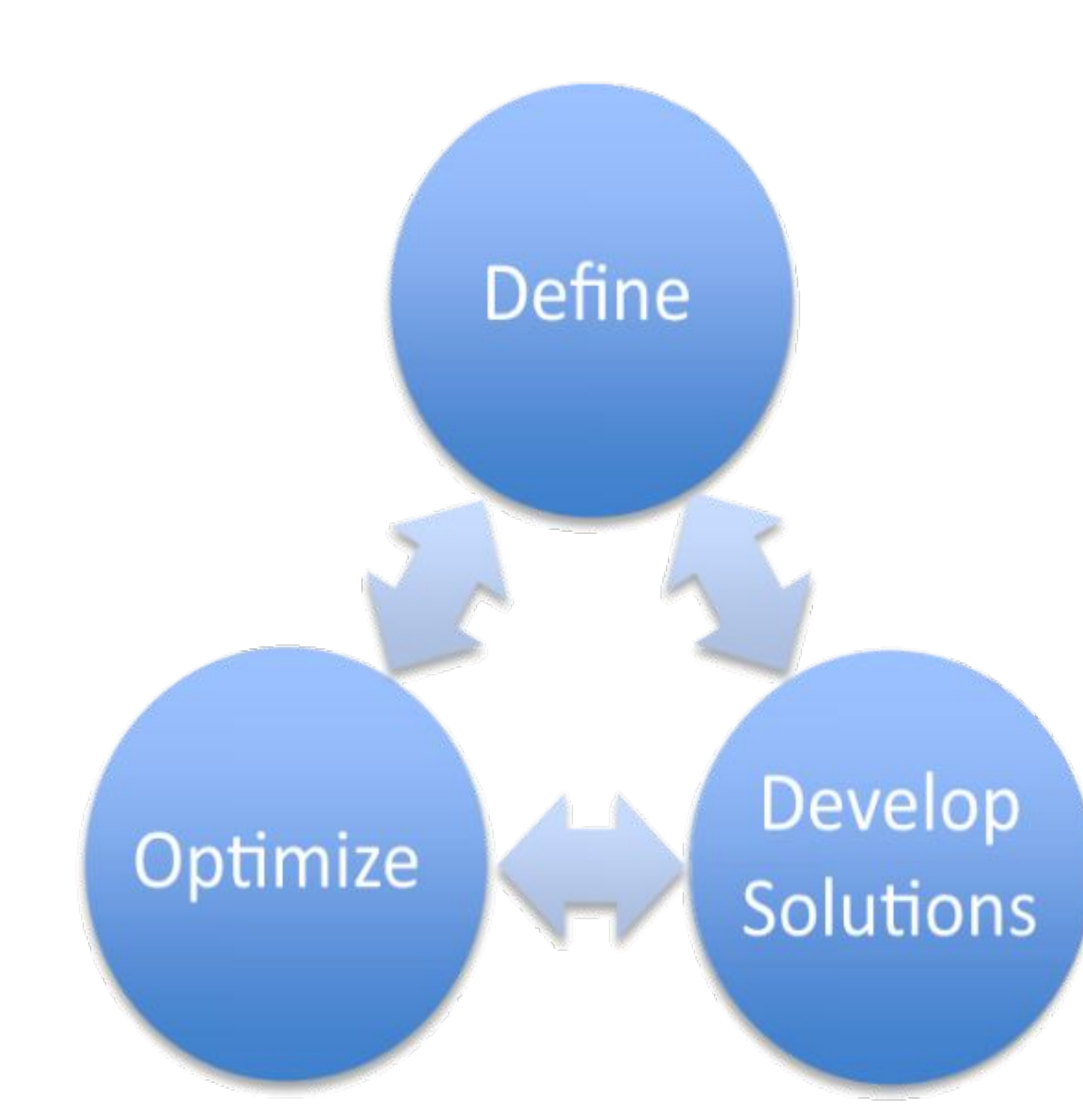
Figure 4: Retrieved from
http://ncedservices.org/stem/

\section{References:}

Newley, A., Kaya, E., Deniz, H. \& Yesilyurt, E. (2017, June). 5th Grade Students' Perceptions of Nature of Engineering. Paper presented at 2017 American Society for Engineering Education. Columbus, Ohio, USA

NGSS Lead States. (2013). Next generation science standards: For states, by states. National Academies Press.

Smaldone, R. A., Thompson, C. M., Evans, M., \& Voit, W. (2016). Teaching science through video games. Nature chemistry, 9(2), 97.

\section{Contact Information}

Anna Newley-anewley@sonoranschools.org

Middle School Science Teacher

Elementary Science Lab

Middle School Hummingbird Robotics

Elementary Finch Robotics

High School FTC Robotics

Sonoran Science Academy-Phoenix

4837 E. McDowell

Phoenix, AZ 85008

6022449855 ex. 101

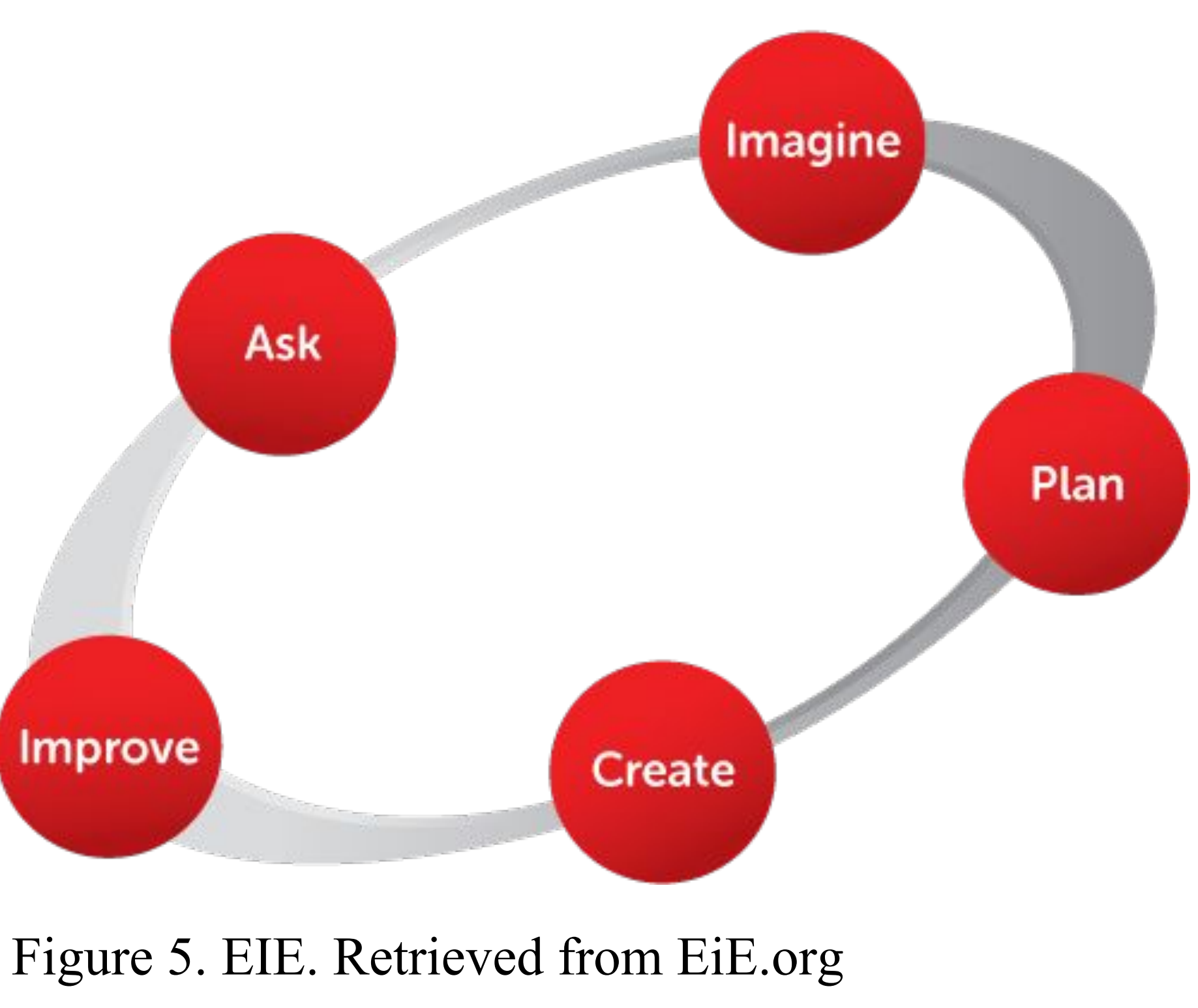

ure 5. EIE. Retrieved from EiE.org 